\title{
On the Allocation of Credit and Aggregate Fluctuations
}

\author{
Orlando Gomes*
}

\author{
Contents: 1. Introduction; 2. The Analytical Framework; 3. Dynamics; 4. Policy Implications \\ and Conclusions. \\ Keywords: Financial development, Credit to consumption, Endogenous growth, Endogenous \\ cycles, Nonlinear dynamics. \\ JEL Code: 016, E32, C61.
}

Recent literature on financial development and growth has highlighted the possibility of endogenous business cycles arising for particular levels of a given credit multiplier. These studies concentrate on loans directed to the productive activity and neglect the role of credit to consumption. In this paper, we consider an endogenous growth model, where a representative agent must choose how to allocate credit; basically, the agent considers a simple rule where the share of credit to consumption reacts to deviations of the consumption - wealth ratio relatively to the corresponding steady state level. The setup generates nonlinear dynamics, which are analyzed both locally and globally.

Literatura recente sobre crescimento e desenvolvimento financeiro tem salientado a possibilidade de ciclos económicos endógenos que surgem para determinados valores de um dado multiplicador de crédito. Estes estudos concentram-se em empréstimos dirigidos à actividade produtiva e negligenciam o papel do crédito ao consumo. Neste artigo, considera-se um modelo de crescimento endógeno, onde um agente representativo tem de escolher como afectar o crédito; basicamente, o agente considera uma regra simples de acordo com a qual a fraç̧ão de crédito para consumo reage a desvios do rácio consumo - riqueza relativamente ao correspondente nível de equilíbrio. Este ambiente gera dinâmica não linear, a qual é analisada localmente e globalmente.

\section{INTRODUCTION}

Beginning with the pioneer work of Stiglitz and Weiss $(1981,1983)$, the issue of constraints to credit has progressively gained a place of its own in the study of macroeconomics. It is crucial to recognize

*Instituto Superior de Contabilidade e Administração de Lisboa (ISCAL) and Unidade de Investigação em Desenvolvimento Empresarial [UNIDE/ISCTE] E-mail: omgomes@iscal.ipl.pt 
and understand that the market for credit has special features that must be carefully analyzed in order to better understand aggregate phenomena. Stiglitz and Greenwald (2003) clearly state the problem at hand,

"Nobody cares who supplies chairs or steel to a market, or who buys chairs or steel from the market. That is one of the wonderful things about competitive markets - they are entirely non-discriminatory.

However, credit is totally different. Supplying credit to John Rockefeller is different from supplying credit to Donald Trump or to anyone else. The terms on which credit will be supplied will depend on judgements about the likelihood that the loan will be repaid. That depends in turn on judgements about the financial position and incentive structures facing the individual or firm to whom credit is lent. (...)

The information problems just described imply that capital markets behave markedly different from conventional markets (...) the information problems may easily give rise to credit rationing." (pages 30-31).

Under this reasoning, borrowing constraints are likely to arise and they can be understood in two ways: first, credit rationing may be thought as a sign of financial underdevelopment, that is, the financial system is unable to find mechanisms to overcome information asymmetries and improve credit worthiness. Second, credit constraints can be interpreted as a sign of precautionary behaviour that avoids financial crisis; in this sense, a too high credit multiplier can be seen not as an indication of a well structured and developed financial system, but as revealing a somehow reckless and imprudent system that at any time may fail to fulfil its market functions as the share of agents failing to pay their debts increases. Banks can contribute to an excessively high credit multiplier if, for instance, they adopt an optimistic judgement regarding business risks or if they reveal, on any other way, a lack of capacity to assess the true probability of default by firms and households. The model to develop below will precisely reveal a dynamic behaviour where economies grow faster with a larger credit multiplier until a threshold is attained; after this point, instability will prevail, and this result can be interpreted as arising from excess of credit in the absence of regulatory measures.

In this paper, we are particularly concerned with the relation between financial development / borrowing constraints and growth, a theme largely discussed in the literature, as in Kyotaki and Moore (1997), Levine (1997), Aghion et al. (1999) and Amable et al. (2004), among others. These authors search for a relation between the extent of borrowing constraints in an economy and the persistence of business cycles. Two papers in particular relate to the analysis we intend to undertake: Aghion et al. (2004) and Caballé et al. (2006) propose theoretical frameworks where the growth - cycles finance setup is able to generate endogenous cycles, similar in nature to the ones that are found in the analysis of deterministic Real Business Cycles (RBC) models with production externalities, as the ones by Christiano and Harrison (1999) and Guo and Lansing (2002). The similarity has to do with the fact that it is solely the mechanics of the purely deterministic theoretical structure that conducts to the observation of long term fluctuations, without the need of considering any exogenous perturbation, which is a central feature on the RBC explanatiodn of cycles.

Our framework considers some original features relatively to the benchmark analysis in this field. First, the growth setup corresponds to an endogenous growth model; in particular, we take a simple one input AK production function. Second, although we consider a generic constraint on credit that is similar to the one in the literature (namely, the kind of linear constraint introduced by Bernanke and Gertler (1989)), we allow for the existence of two kinds of credit: credit to investment and credit to consumption. We assume, as well, that the representative agent takes a simple rule when determining the shares of borrowing for each possible end; the rule is based on consumer sentiment and functions as follows: if the wealth-consumption ratio in the economy, in some time moment, is higher than a given benchmark value, then the agents become optimistic about future possibilities regarding consumption 
(they perceive that there is room for a future faster growth of consumption relatively to wealth), and thus they will attach more credit to consumption and less to productive uses (otherwise in the opposite case).

The simple framework we choose to work with is able to contain various long term dynamic outcomes for different values of parameters. Local dynamics analysis reveals that bifurcations are likely to occur as we change, for instance, the value of the credit multiplier. Global analysis confirms that bifurcations occur, implying the transition from a region of fixed point stability to invariant cycles and chaotic motion. Our main conclusion will be the one that less constraints on borrowing are growth enhancing until a given point where cyclical motion and, later, instability become dominant for an excessively loose credit policy.

This paper is organized as follows. Section 2 presents the model; Section 3 deals with the dynamic behaviour and Section 4 contains some final comments.

\section{THE ANALYTICAL FRAMEWORK}

Assume a conventional endogenous growth model, where a representative agent maximizes expected utility under an infinite horizon. The objective function of this agent is, in moment $t=0$,

$$
V_{0}=\sum_{t=0}^{+\infty} \beta^{t} E_{0}\left[U\left(c_{t}\right)\right]
$$

Parameter $\beta>0$ corresponds to a discount factor, $c_{t}$ represents real consumption, ${ }^{1}$ and $E_{0}$ is an expectations operator. The utility function $U$ will take the simplest functional form under the usual assumption of decreasing marginal utility, i.e., $U\left(c_{t}\right)=\ln c_{t}$. The maximization of $V_{0}$ is subject to a resource constraint that will represent the process of wealth accumulation. Wealth dynamics is given by

$$
w_{t+1}=y_{t}-r b_{t}-\left[c_{t}-\left(1-v_{t}\right) b_{t}\right], \quad w_{0} \text { given. }
$$

In difference equation (2), $y_{t}$ respects to income, $b_{t}$ is the amount of financial resources available to borrow in moment $t, r$ represents the nominal interest rate and $1-v_{t} \in(0,1)$ is the share of available credit that the representative agent chooses to allocate to consumption. Note that $c_{t}$ represents overall consumption, and thus tomorrow's wealth corresponds to today's income less interest payments and less the part of consumption that corresponds to resources directly withdrawn from contemporaneous output.

We assume an endogenous growth economy and, thus, income is generated through a simple AK production function, $y_{t}=A k_{t}$, where $k_{t}$ represents physical capital and $A>0$ is a technological index. Considering, as well, that capital fully depreciates in each time period, capital will equal investment $\left(i_{t}=k_{t}\right)$; furthermore, we should regard that the resources available to invest in a given period $t$ are the available wealth plus the credit resources directed to the production of final goods, that is, $i_{t}=w_{t}+v_{t} b_{t}$. Therefore, the production function can be rewritten as $y_{t}=A\left(w_{t}+v_{t} b_{t}\right)$. Finally, the structure of the wealth constraint becomes complete with the consideration of a credit multiplier. Following the literature on this topic, we consider that the available credit is a linear function of wealth: $b_{t}=\mu w_{t}$.

Equation (2) is equivalent to the following,

$$
w_{t+1}=\left[A+\mu\left(A v_{t}-r\right)\right] w_{t}-\left[c_{t}-\left(1-v_{t}\right) \mu w_{t}\right]
$$

\footnotetext{
${ }^{1}$ This variable, as the following ones, may be understood as a level or as a per capita variable, since we do not consider population growth.
} 
In our model, we assume that marginal returns are higher than the market interest rate $(A>r)$, implying that borrowing resources will be integrally used by private agents.

An additional assumption is that the representative consumer, when solving the optimal program in $t=0$, takes the expected value of $v_{t}$ as a constant. Consumption decisions are taken assuming that the shares of credit allocated to consumption and to investment do not vary in the future relatively to an equilibrium expected value $E v_{t}=\bar{v}$ that remains over time. We present this value in the form $\bar{v}=\frac{1}{2}-\frac{1}{\pi} \operatorname{arctg}(a)$, with $a \in \mathbb{R}$.

The previous value guarantees that there is always some borrowing resources allocated to both uses, because the following conditions hold, $\lim _{a \rightarrow-\infty} \bar{v}=0 ; \lim _{a \rightarrow+\infty} \bar{v}=1$. Observe also that $a=0$ means that there are equivalent shares of credit for both uses and that $a>0 \Rightarrow \bar{v}>0.5$ and $a<0 \Rightarrow \bar{v}<0.5$.

Solving problem (1) subject to (3) is straightforward. The computation of first order conditions implies the following rule of motion for consumption,

$$
c_{t+1}=\beta[A+\mu(1-r)+\mu(A-1) \bar{v}] c_{t}
$$

Under (4), consumption grows at a constant rate over time. Furthermore, looking at (3), and assuming that $v_{t}$ is indeed a constant value in the steady state, wealth will grow at the same rate in the long run. Therefore, a first relevant result is stated,

Proposition 2.1. In the long term, credit availability is growth enhancing if $\bar{v}>\frac{1-r}{1-A}$. In this circumstance, both the growth rate of consumption and the growth rate of wealth rise with the credit multiplier.

Proof. Just compute the derivative $\partial g / \partial \mu$, with $g$ the long term growth rate. The derivative is $\partial g / \partial \mu=$ $\beta[1-r+(A-1) \bar{v}]$. This is a positive value under the inequality in the proposition

Note that imposing $A>1$ is a sufficient condition for a positive relation between borrowing capacity and growth. A high level of technology works as a guarantee that credit benefits economic performance.

Although the representative consumer solves the intertemporal problem as if $v_{t}$ was a constant share, the agent will end up by breaking her own initial rule. In particular, we assume that the agent is sensitive to deviations of the consumption-wealth ratio relatively to a benchmark equilibrium value: when the value of this ratio is below the reference level, this means that the accumulation of wealth is relatively above the predicted value (or, what is the same, consumption is relatively below the expected outcome); as a result, the representative agent becomes optimistic in what concerns future economic performance and consequently trades some credit to investment for credit to consumption. In periods where the consumption-wealth ratio rises above the perceived equilibrium value, consumers' sentiment changes as they realize the need for taking precautionary measures, and this pushes the representative agent to increase the value of share $v_{t}$.

We define $\psi_{t} \equiv c_{t} / w_{t}$ and consider a benchmark value $\bar{\psi}$ (which will correspond to the steady state ratio to be derived below), and adopt the following share rule,

$$
1-v_{t}=\frac{1}{2}+\frac{1}{\pi} \operatorname{arctg}\left[(a+\kappa) \frac{\bar{\psi}}{\psi_{t-1}}-\kappa\right]
$$

Some comments regarding the shape of (5) are in order. First, there is a time lag in the relation between the consumption-wealth ratio and the share of credit to consumption. This is explained by the idea that individuals take one time period to adjust their borrowing allocation decisions as a response to the evolution of economic aggregates' values. Second, there is a relation of opposite sign between $\psi_{t-1}$ and $1-v_{t}$; as we have previously remarked, when consumption rises above 'normal', the agent becomes pessimistic or increasingly prudent and as a result less credit will be directed to consumption (as the agent expects the consumption-wealth relation to return to 'normal' in the following time periods). Third, when $\psi_{t-1}=\bar{\psi}$, we have $1-\bar{v}=\frac{1}{2}+\frac{1}{\pi} \operatorname{arctg}(a)$, an expression that is equivalent to the one 
presented above for $\bar{v}$. Fourth, the new parameter, $\kappa$, is positive, and it obeys to condition $\kappa>-a$. Fifth, the lower boundary of share $1-v_{t}$ is no longer 0 ; with (5), we have $1-v_{t} \in\left[\frac{1}{2}+\frac{1}{\pi} \operatorname{arctg}(-\kappa) ; 1\right]$. This is a slight change, in the sense that taking a relatively high level of $\kappa$, the lower boundary will be close to 0 ; for instance, and $\kappa=15 \Rightarrow 1-\bar{v}=0.021$ and $\kappa=100 \Rightarrow 1-\bar{v}=0.003$.

Figure 1 presents the relation between the consumption-wealth ratio and the credit share. We display two panels. The one on the left respects to credit to consumption and the one on the right respects to credit to investment.

Figure 1: The dynamics of credit shares.
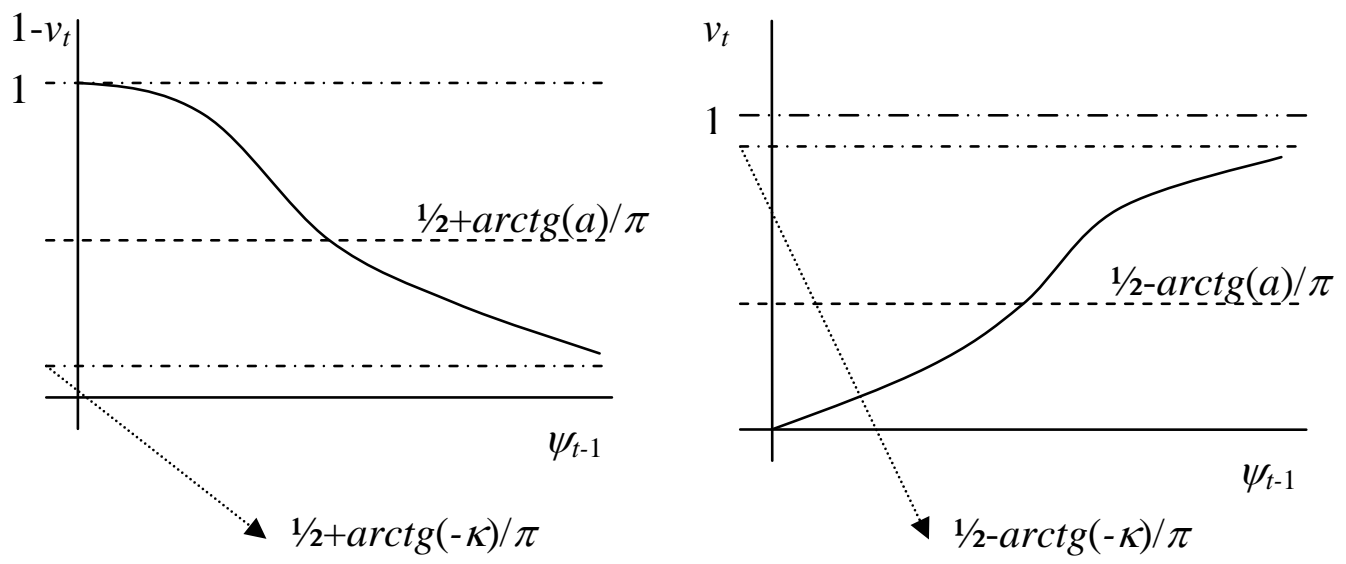

The representative agent derives a consumption evolution rule by assuming a constant $v_{t}$, but in practice she violates this rule, and therefore the dynamics of wealth are characterized by (3) and (5). Hence, the equation of motion for the consumption-wealth ratio comes

$$
\psi_{t+1}=\frac{\beta \phi}{A+\mu(1-r)+\mu(A-1) v_{t}-\psi_{t}} \psi_{t}
$$

with $\phi \equiv A+\mu(1-r)+\mu(A-1) \bar{v}$. Condition $\phi>0$ is required to guarantee a positive steady state value of the consumption-wealth ratio.

Taking equation (6) and a version of (5) one time period ahead, we get a two-dimensional system with two endogenous variables, from which the dynamics of the described economy can be studied. Such an analysis is the subject of the next section. For now, we just relate the level of barriers to credit with the long term share of consumption out of wealth.

Proposition 2.2. The same condition that makes credit availability growth enhancing, implies that the steady state consumption-wealth ratio is as much larger as the higher is the credit multiplier.

Proof. Defining the steady state as the locus where $v_{t}=\bar{v}$ and $\psi_{t+1}=\psi_{t}=\bar{\psi}$, it is straightforward to realize that a unique steady state exists for the already presented equilibrium credit share and for $\bar{\psi}=(1-\beta) \phi$. Computing the derivative $\partial \bar{\psi} / \partial \mu$, we understand that $\bar{\psi}$ rises with $\mu$ if $\bar{v}=\frac{1-r}{1-A}$

A sufficient condition for lower credit constraints to work in favour of a more favourable consumption-wealth relation (from the consumer's point of view, of course) is that $A>1$. Hence, high technology levels allow borrowing availability not only to stimulate growth, but also to stimulate increased levels of long run consumption. 


\section{DYNAMICS}

\subsection{Local dynamics}

Take the pair of equilibrium values $(\bar{\psi}, \bar{v})$ and linearize the derived system in the vicinity of this point. The linearized system is

$$
\left[\begin{array}{c}
\psi_{t+1}-\bar{\psi} \\
v_{t+1}-\bar{v}
\end{array}\right]=\left[\begin{array}{cc}
1 / \beta & -(1-\beta) \mu(A-1) / \beta \\
\frac{a+\kappa}{\pi\left(1+a^{2}\right)(1-\beta) \phi} & 0
\end{array}\right] \cdot\left[\begin{array}{c}
\psi_{t}-\bar{\psi} \\
v_{t}-\bar{v}
\end{array}\right]
$$

The trace and determinant of the Jacobian matrix are, respectively, $\operatorname{Tr}(J)=1 / \beta$ and $\operatorname{Det}(J)=$ $\frac{(a+\kappa) \mu(A-1)}{\pi\left(1+a^{2}\right) \beta \phi}$. The trace is a value higher than $1 ;^{2}$ the determinant is positive as long as $A>1$.

Proposition 3.1. Stability results are as follows:

a) Convergence to the steady state is guaranteed under $1-\beta<\frac{(a+\kappa) \mu(A-1)}{\pi\left(1+a^{2}\right) \phi}<\beta$;

b) Saddle-path stability requires $-(1+\beta)<\frac{(a+\kappa) \mu(A-1)}{\pi\left(1+a^{2}\right) \phi}<1-\beta$;

c) Instability prevails under $\frac{(a+\kappa) \mu(A-1)}{\pi\left(1+a^{2}\right) \phi}<-(1+\beta)$ or $\frac{(a+\kappa) \mu(A-1)}{\pi\left(1+a^{2}\right) \phi}>\beta$.

Bifurcations occur at the following points:

d) $\frac{(a+\kappa) \mu(A-1)}{\pi\left(1+a^{2}\right) \phi}=\beta$ (Neimark-Sacker bifurcation);

e) $\frac{(a+\kappa) \mu(A-1)}{\pi\left(1+a^{2}\right) \phi}=1-\beta$ (Fold bifurcation);

f) $\frac{(a+\kappa) \mu(A-1)}{\pi\left(1+a^{2}\right) \phi}=-(1+\beta) .^{3}$

Proof. To prove the conditions in the proposition, we just have to solve the stability system, 1 $\operatorname{Det}(J)>0 ; 1-\operatorname{Tr}(J)+\operatorname{Det}(J)>0 ; 1+\operatorname{Tr}(J)+\operatorname{Det}(J)>0$. If these three inequalities hold, then condition $a$ ) is found. Bifurcations $d$ ), e) and $f$ ) are encountered when strict equalities replace, respectively, each one of the upper inequalities. Saddle-path stability arises for the set of conditions $1-\operatorname{Det}(J)>0 ; 1-\operatorname{Tr}(J)+\operatorname{Det}(J)<0 ; 1+\operatorname{Tr}(J)+\operatorname{Det}(J)>0$ and, finally, instability takes place under $1-\operatorname{Det}(J)<0$ or if $1-\operatorname{Det}(J)>0 ; 1-\operatorname{Tr}(J)+\operatorname{Det}(J)<0 ; 1+\operatorname{Tr}(J)+\operatorname{Det}(J)<0$.

Note that under condition $A>1$, we tighten the range of possible stability outcomes; specifically, only Neimark-Sacker or fold bifurcations become possible. Figure 2 displays the stability results by drawing a simple diagram relating trace and determinant.

\subsection{Global dynamics}

Local dynamics, as depicted in Figure 2, reveals that a relatively large set of stability results are possible depending on parameter values. Adding an analysis of global dynamics further results are revealed.

We can only proceed with an analysis of global dynamics by considering numerical examples. Therefore, we choose an illustrative particular case. Let $\beta=0.96$ (a discount rate of $4.17 \%$ ), $r=0.03$, $a=-1$ (this value means that three quarters of the equilibrium borrowing capabilities are directed to investment: $\bar{v}=0.75$ ), $\kappa=15$ (a sufficiently high level in order for the upper limit of $v_{t}$ to be close to 1), and $A=10$ (since $A>1$, we restrict the analysis to the case where the determinant of the Jacobian matrix is positive). The credit multiplier will be the bifurcation parameter, that is, we allow its value

\footnotetext{
${ }^{2}$ For reasonable values of the discount rate of future utility, the trace will be higher but close to 1 ; for the sake of our analysis, we exclude discount rates equal or above $100 \%$, meaning that $1 / \beta<2$.

${ }^{3}$ According to Medio and Lines (2001), p. 160, in this case we cannot refer to a flip bifurcation because although one of the eigenvalues of the Jacobian matrix is equal to -1 , one of the required conditions for a flip bifurcation fails to hold; namely, $\operatorname{Tr}(J) \in(-2,0)$ is not observed.
} 
Figure 2: Stability analysis in the Trace-Determinant diagram.

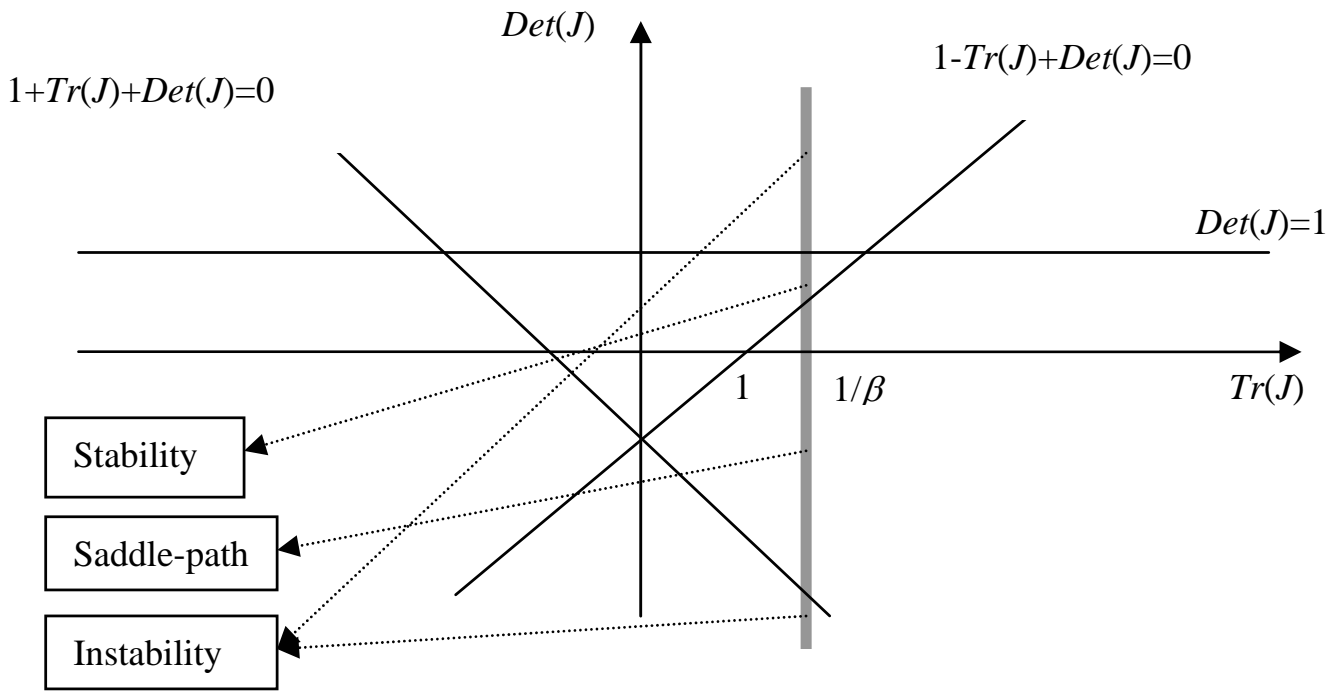

to vary in order to perceive how the bifurcations take place and how they impact on our endogenous variables' behaviour. We must also choose the initial values $v_{0}$ and $\psi_{0}$; the first is irrelevant in terms of dynamic results; the second may provoke slight changes on the basin of attraction. In our specific example, we consider $\psi_{0}=0.5{ }^{4}$

Figure 3 presents the bifurcation diagram relating to share $v_{t}$. The occurrence of a Neimark-Sacker bifurcation is evidenced and we regard that areas of chaotic motion alternate with cycles of various periodicities.

Figure 4 represents the long term time series of this share for a value of financial development for which endogenous fluctuations exist $(\mu=7)$. Because the behaviour in time of the consumption-wealth ratio depends on $v_{t}$, then this ratio will exhibit as well endogenous cycles. ${ }^{5}$

To confirm the presence of chaos for given values of $\mu$, observe Figure 5, that displays Lyapunov characteristic exponents ( $L C E s)$. These are a measure of exponential divergence of nearby orbits, a well accepted description of systems exhibiting chaos. A positive $L C E$ in a two-dimensional system reveals the presence of chaotic motion, and we observe that such condition holds for some values of $\mu$.

\footnotetext{
${ }^{4}$ There is a result that seems apparently odd when we choose the above set of parameter values. We have stated that the economy grows in the long run at rate $\beta \phi-1$. In our example, assuming for instance $\mu=7$ (a value that we will regard to give place to endogenous fluctuations), then $\phi=64.04$ and thus the economy would grow at a rate of $6,047.84 \%$ per period. However, this is not really a problem; it is just a question of scale. If we say that the economy grows at some rate $\gamma$ different from the one above, then $c_{t}$ and $w_{t}$ are not the original variables that truly characterize the economy's behaviour. These would be $\widetilde{c}_{t}=\frac{c_{t}}{\left(\frac{\beta \phi}{1+\gamma}\right)^{t}}$ and $\widetilde{w}_{t}=\frac{w_{t}}{\left(\frac{\beta \phi}{1+\gamma}\right)^{t}}$. Because $\psi_{t}=\frac{c_{t}}{w_{t}}=\frac{\widetilde{c}_{t}}{\widetilde{w}_{t}}$, the system under analysis is exactly the same for one or for the other set of variables.

${ }^{5}$ The figures relating to global dynamics are drawn using IDMC software (interactive Dynamical Model Calculator). This is a free software program available at www.dss . uniud.it/nonlinear, and copyright of Marji Lines and Alfredo Medio.
} 
Figure 3: Bifurcation diagram $\left(v_{t} ; \mu\right)$.

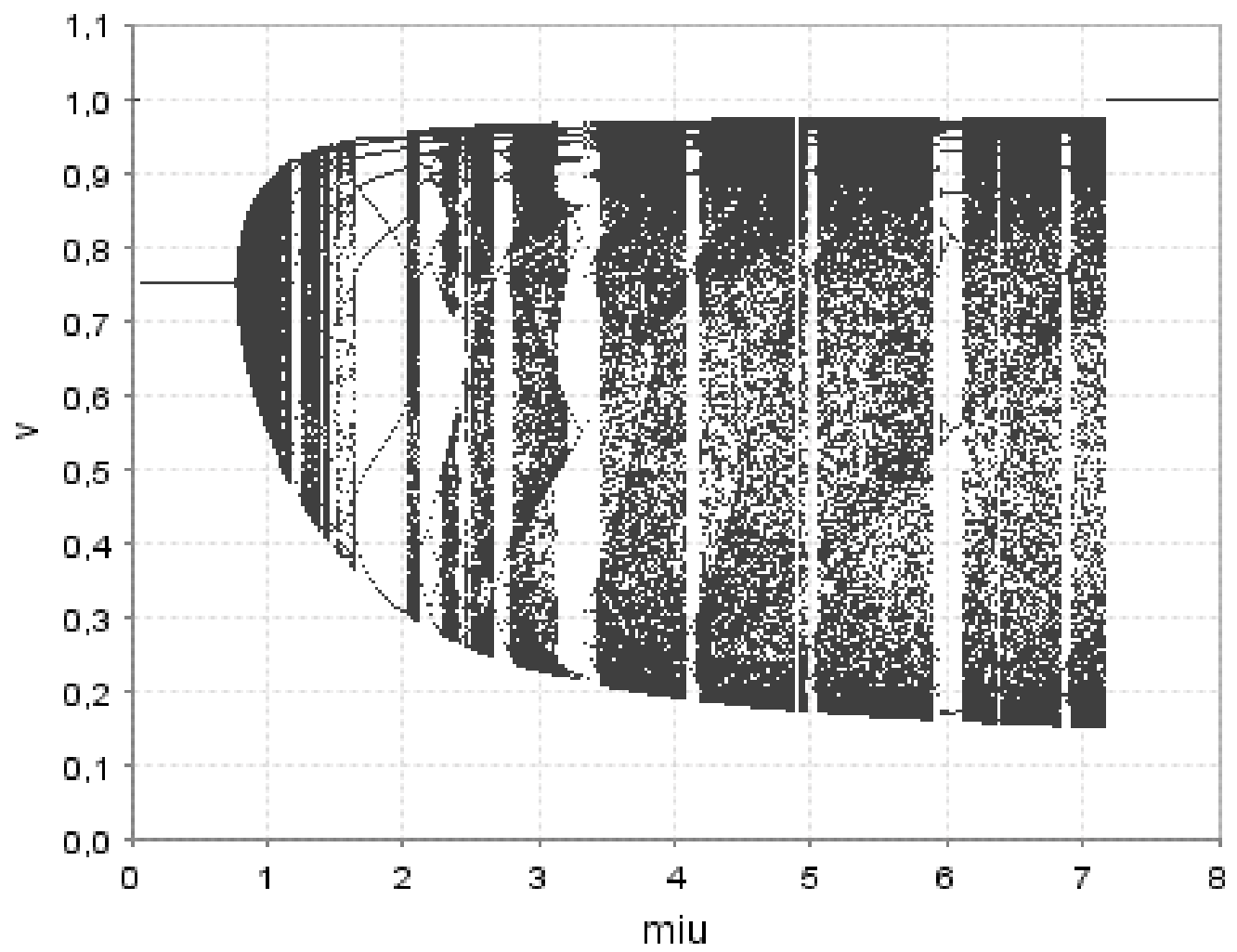


Figure 4: Time series of share $v_{t}(\mu=7)$.

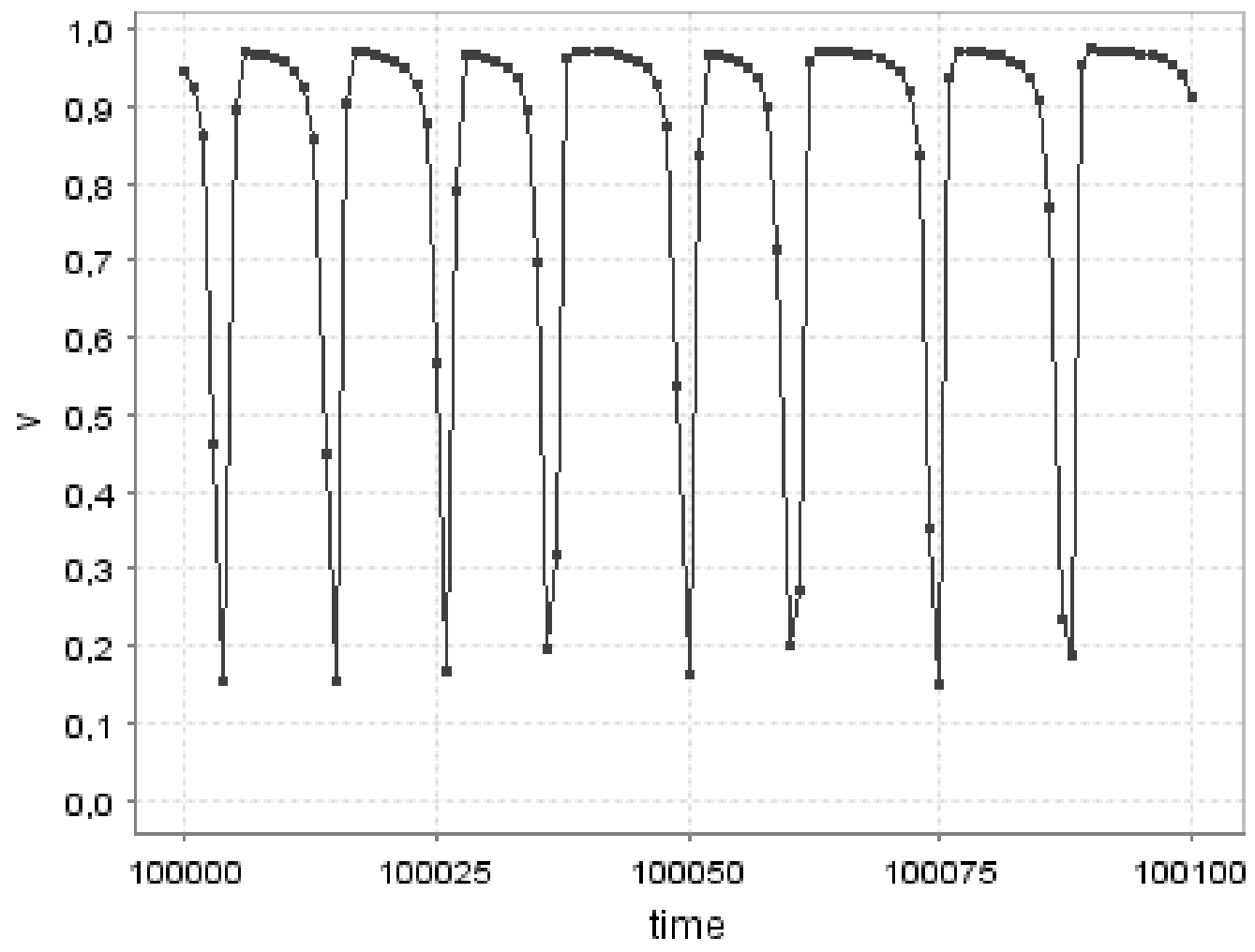


Figure 5: Lyapunov characteristic exponents

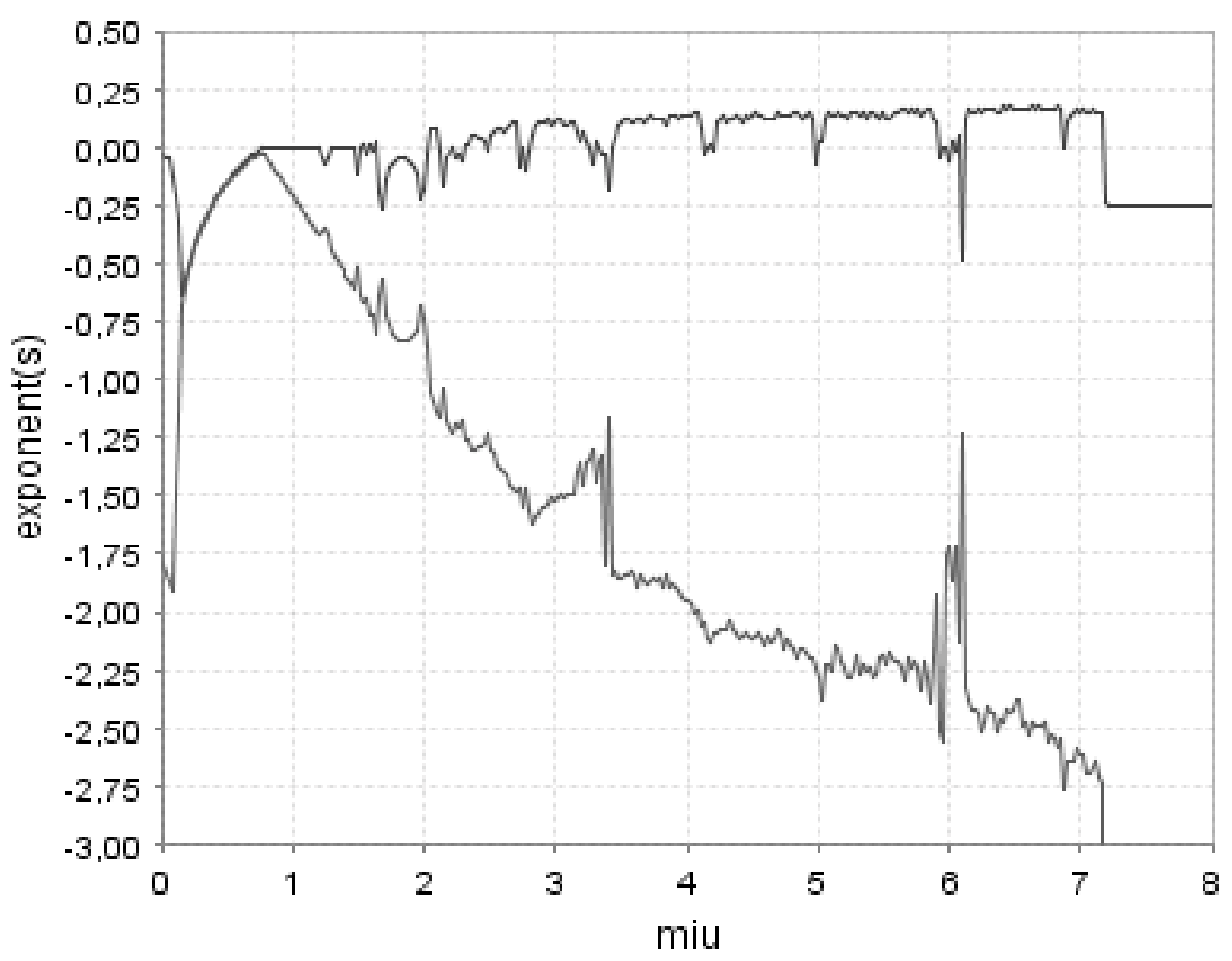




\section{POLICY IMPLICATIONS AND CONCLUSIONS}

The proposed model of growth and financial development produces meaningful results, with relevant policy implications, that we now systematize:

1) The higher the level of technological development, the better the economy is able to profit from credit availability. In fact, our setup establishes a link between the financial sector and the effort related to R\&D activities. Only strong technological capabilities produce the ability for a higher credit multiplier to increase the long run growth rate and the steady state consumption-wealth ratio. Therefore, our first policy result respects to the necessity of creating an environment capable of developing simultaneously the financial sector and the production of ideas and techniques.

2) Stability requires a mild condition (the first condition in Proposition 3). This means that extreme values of parameters tend to compromise stability; for instance a too high or too low long term allocation of credit to one of the two possible uses does not favour a stable result.

3) The bifurcation diagram in Figure 3 indicates that an exaggerated availability of credit leads first to cycles of increasing amplitude and finally to an unstable outcome where all credit is allocated to production and no credit goes to consumption. This may be interpreted as a case in which a financial crisis occurs and consumers become totally risk averse. They will not borrow at all to increase today's levels of consumption.

4) Our main result is that the myopic attitude of consumers (that maximize utility in order to get a constant rate of consumption growth while simultaneously responding to economic fluctuations to support borrowing decisions) is the central source of eventual business cycles. In this sense, cycles are self-fulfilling and are truly the result of the consumer sentiment more than the result of the functioning of financial markets. Nevertheless, given that different levels of available credit produce distinct stability results, public authorities will have knowledge of the fact that consumer sentiment will lead to pronounced business cycles only for some financial conditions; other financial scenarios are robust to the behaviour of private agents.

\section{BIBLIOGRAPHY}

Aghion, P., Bacchetta, P., \& Banerjee, A. (2004). Financial development and the instability of open economies. Journal of Monetary Economics, 51:1077-1106.

Aghion, P., Banerjee, A., \& Piketty, T. (1999). Dualism and macroeconomic volatility. Quarterly Journal of Economics, 114:1357-1397.

Amable, B., Chatelain, J. B., \& Ralf, K. (2004). Credit rationing profit accumulation and economic growth. Economics Letters, 85:301-307.

Bernanke, B. \& Gertler, M. (1989). Agency costs, net worth, and business fluctuations. American Economic Review, 79:14-31.

Caballé, J., Jarque, X., \& Michetti, E. (2006). Chaotic dynamics in credit constrained emerging economies. Journal of Economic Dynamics and Control, 30:1261-1275.

Christiano, L. \& Harrison, S. (1999). Chaos, sunspots and automatic stabilizers. Journal of Monetary Economics, 44:3-31.

Guo, J. T. \& Lansing, K. J. (2002). Fiscal policy, increasing returns and endogenous fluctuations. Macroeconomic Dynamics, 6:633-664. 
Kyotaki, N. \& Moore, J. (1997). Credit cycles. Journal of Political Economy, 105:211-248.

Levine, R. (1997). Financial development and economic growth: Views and agenda. Journal of Economic Literature, 35:688-726.

Medio, A. \& Lines, M. (2001). Nonlinear dynamics: a primer. UK Cambridge University Press, Cambridge.

Stiglitz, J. E. \& Greenwald, B. (2003). Towards a new paradigm in monetary economics. In The Raffaele Mattioli Lecture Series. Cambridge University Press, Cambridge.

Stiglitz, J. E. \& Weiss, A. (1981). Credit rationing in markets with imperfect information. American Economic Review, 71:333-421.

Stiglitz, J. E. \& Weiss, A. (1983). Incentive effects of termination: Applications to the credit and labor markets. American Economic Review, 73:912-927. 